\title{
TERRITÓRIO: UMA ESTRATÉGIA ÀS POLÍTICAS SOCIAIS
}

\author{
TERRITORY: A STRATEGY FOR SOCIAL POLICIES
}

\section{RESUMO}

Pauta-se no pressuposto que o conceito de território constitui-se um alicerce fundamental na elaboração das políticas sociais, uma vez que permite uma compreensão da problemática das dinâmicas socio-territoriais. Essa categoria de análise geográfica pode auxiliar as políticas sociais por carregar conteúdo interdisciplinar e incorporador. O processo de integrar o conceito e efetuar a leitura territorial é fundamental para o desenvolvimento das políticas públicas e das tomadas de decisão nos órgãos públicos. Tendo em vista que as expressões socio identitárias encontram-se no território, o presente artigo busca refletir sobre a ótica dos autores que discorrem sobre o conceito pautada na materialidade e imaterialidade, não como duas coisas distintas, mas como dois objetos integradores para compreensão efetiva das manifestações objetivas e subjetivas encontradas no território.

Palavras-chave: Território. território usado. Territorialidade. políticas públicas. assistência social.

\section{ABSTRACT}

It is based on the assumption that the concept of territory constitutes a fundamental foundation in the elaboration of social policies, since it allows an understanding of the problematic of the socio-territorial dynamics. This category of geographic analysis can assist social policies by loading interdisciplinary and incorporating content. The process of integrating the concept and carrying out the territorial reading is fundamental for the development of public policies and decision-making in public agencies. Considering that the socio-ideological expressions are in the territory, the present article seeks to reflect on the optics of the authors who discuss the concept based on materiality and immateriality, not as two distinct things, but as two integrating objects for effective comprehension of the manifestations objective and subjective found in the territory.

Keywords: Territory. territory used. Territoriality. public policies. social assistance.

\author{
Caio Cezar Cunha ${ }^{\text {a }}$ \\ Ideni Terezinha Antonello ${ }^{a}$ \\ a Universidade Estadual de Londrina \\ (UEL), Londrina, PR, Brasil
}

DOI: 10.12957/geouerj.2020.36573

Correpondência: caioccunha89@gmail.com

Recebido em: 6 fev. 2018

Aceito em: 8 fev 2020 


\section{INTRODUÇÃO}

O conceito interdisciplinar que se relaciona com diversas áreas e instrumentos de análise discutido no artigo é o território. Antes de tudo, é bom recordar que o geógrafo Milton Santos já citava em sua obra "O retorno do território" de 2005 que é o uso do território, e não o território em si mesmo, que faz dele objeto da análise social. Torna-se conceito a partir do momento em que analisamos seu uso, o território em si, pelo senso comum é tido apenas como uma delimitação, seja ela política entre as nações, os estados, municípios ou até muros. Sobre muros há exemplos históricos a citar, desde muros criados pelo medo até muros construídos para dividir uma cultura ou um ideal político. Todos esses exemplos podem ser denominados de territórios, mas o que está por trás desta criação? Essa é a pergunta que motiva os geógrafos estudarem o uso do território, isto é, analisar seu contexto histórico real - pois conforme afirma Milton Santos (2000), é o seu uso que vai produzir o que ele é, é a partir do chão, das subjetividades vivenciadas que ali ocorreram, que torna o território um objeto de análise social.

Este conceito, abrangente e debatido em diversos meios, merece atenção por ter uma variedade de interpretações e autores que o debatem. Tendo em vista tal necessidade, na elaboração deste artigo, buscase trazer o conceito de território com o objetivo de clarear seus princípios e possibilitar a reflexão da importância de leitura territorial para a compreensão da problemática social que envolve a pobreza e a cidade, como também atentar para as possíveis contribuições que podem surgir para a concretização do debate no âmbito do SUAS (Sistema Único da Assistência Social), bem como explicitar possibilidades de uso em torno das discussões da territorialização das políticas públicas.

Afim de atender essas expectativas, a metodologia utilizada para a realização deste estudo foi o levantamento de material bibliográfico de alguns dos principais autores que debatem sobre a origem e o objetivo do conceito território no âmbito da política pública e sua real aplicação, tendo em vista que é fundamental esclarecer o conceito e proporcionar direcionamentos que facilitem a ponte entre conhecimento teórico e o conhecimento empírico. Dessa forma, o estudo se desenvolve divido em duas partes, sendo a primeira uma reflexão interdisciplinar em que abordamos a questão do território incorporado às políticas sociais e a segunda o território como sustentáculo na elaboração e aplicabilidade das políticas sociais.

\section{Reflexão interdisciplinar: Do território geográfico ao território político-social}

Quando discutimos territorialização junto as políticas sociais buscamos efetuar analises contributivas para o processo de construção desta temática, cuja caso brasileiro é historicamente marcado pela (re)produção das desigualdades sociais marcadas nos territórios de maneira heterogênea. Nessa perspectiva, entender os desdobramentos do processo de segregação socio territorial é fundamental para amparar as tomadas de decisões da gestão local, cujo o propósito são as demandas sociais da população. 
O território, tratado como um conceito central na geografia, basicamente diz respeito a espacialidade humana. É inegável que diversas áreas do conhecimento se apropriam deste conceito cada uma com um enfoque centrado em uma determinada perspectiva.

Partindo do pressuposto que o território é criado, e intimamente ligado a história da construção do território em si, é possível notar em primeiro instante que o mesmo nasce do poder. O ato de criar um limite, uma fronteira ou um muro e chamar aquela "área de meu", ter poder sobre ela, é a expressão de uma herança patriarcal colonialista, bastante presente na guerra para obter controle e poder, o território não pode(ria) ser usado no mesmo viés nas discussões das políticas sociais.

O conceito de território é utilizado em uma série de casos que apresentam desde sua manifestação mais materialista até a mais cultural e simbólica. Para tal, torna-se necessário analisar algumas discussões intrínsecas a geografia desde seus primeiros diálogos quanto a categoria geográfica, como também, confrontar as discussões utilizadas em outras áreas do conhecimento, neste caso, do Serviço Social que, de acordo com as demandas sociais nos últimos anos, vem se apropriando deste conceito para fundamentar suas análises na elaboração e aplicabilidade nas políticas sociais.

Nessa ótica, geógrafos contemporâneos importantes na construção da discussão em torno do território, deixam claro a abrangência teórica-metodológica que o conceito pode assumir, nesse sentido, Saquet elucida que:

\footnotetext{
[...] o território significa articulações sociais, conflitos, cooperações, concorrências e coesões; é produto de tramas que envolvem as construções (formas espaciais), as instituições, as redes multiescalares, as relações sociais e a natureza exterior ao homem; é objetivo-material e subjetivo-imaterial ao mesmo tempo. (2008, p.88, grifo do autor)
}

Ao possuir tamanha amplitude o conceito de território cria a possibilidade de alicerçar teoricamente outras áreas do conhecimento, Haesbaert ilustra que:

[...] enquanto o geógrafo tende a enfatizar a materialidade do território, em suas múltiplas dimensões (que deve[ria] incluir a interação sociedade-natureza), a Ciência Política enfatiza sua construção a partir de relações de poder (na maioria das vezes, ligada à concepção de Estado); a Economia, que prefere a noção de espaço à de território, percebe-o muitas vezes como um fator locacional ou como uma das bases da produção (enquanto "força produtiva"); a Antropologia destaca sua dimensão simbólica, principalmente no estudo das sociedades ditas tradicionais (mas também no tratamento do "neotribalismo" contemporâneo); a Sociologia o enfoca a partir de sua intervenção nas relações sociais, em sentido amplo, e a Psicologia, finalmente, incorpora-o no debate sobre a construção da subjetividade ou da identidade pessoal, ampliando-o até a escala do indivíduo. (2016, p. 37)

Ao encontrar diversas concepções sobre o território e ao evidenciar inúmeras ciências que dele se utilizam, nota-se que o mesmo já teve uma trajetória histórica diversificada, outras ciências se apropriam do conceito, o que nos faz compreender não só sua amplitude, mas sua capacidade de esclarecer e dialogar desde as questões mais objetivas e materiais que Saquet (2008) coloca, até as análises mais subjetivas e sociais. 
Além de ser um conceito muito utilizado por outras ciências para compreender situações espaciais, o território possui uma carga de significados que merece atenção. $\mathrm{Na}$ Geografia, dentre os conceitos geográficos, podemos associar alguns significados quando discutimos as categorias de análise, o espaço a região, o lugar, a paisagem e o território, cada uma tem seu significado e particularidade ao ser utilizada conforme as abordagens do pensamento geográfico que se enquadram os pesquisadores, mas todas podem ser relacionadas e utilizadas para clarificar analises sobre o espaço-tempo.

Cabe lembrar que o atual objetivo deste artigo não é realizar análise dos conceitos das categorias de análise geográficas, mas sim expor as bases teóricas-metodológicas que a geografia dispõe para a análise espacial, bem como reafirmar e esclarecer o motivo do uso da categoria território dentro das políticas sociais. Nessa perspectiva, Correa defende a geografia como ciência social que:

[...] tem como objetivo de estudo a sociedade que, no entanto, é objetivada via cinco conceitos-chave que guardam entre si forte grau de parentesco pois todos se referem à ação humana modelando a superfície terrestre [...] Cada um dos conceitos-chave acima indicados tem sido objeto de amplo debate, tanto interno como externo à geografia, envolvendo assim não-geógrafos. No bojo do debate cada conceito possui várias acepções cada uma calcada em uma específica corrente de pensamento. (2000, p. 16)

O autor ainda reitera que as categorias de análise geográfica (lugar, região, paisagem, território, espaço) têm sido diferentemente conceitualizadas segundo diversas correntes do pensamento geográfico. Conclui ainda que a forma que os debates ocorrem, tem trazido benefícios a ciência, pois, se revela conflitos, permite, por isso mesmo, avanços na teoria geográfica.

Se analisássemos todas as categorias, notaríamos que todas constituem-se em significados particularizados da atuação humana nas transformações do planeta e da sociedade. Como pontua Rocha (2008) diferentes conceitos, diversas formas de caracterizar essas mudanças, as categorias são produtos originários de cada visão particular de mundo, de cada universo expresso na peculiaridade de cada homem como ser único, de culturas geradas em civilizações singulares. As categorias, são produtos da decorrência da vida, do contato dos homens com outros homens em espaços e tempo desiguais, incrustados em numerosos e distintos universos culturais. Assim, os geógrafos ao longo da trajetória da ciência geográfica buscam a formulação de conceitos que visam entender a relação homem- natureza, os quais estarão intrinsicamente relacionados a abordagem do pensamento geográfico dominante em determinada temporalidade da ciência, por conseguinte vinculada a determinado método científico que sustenta o arcabouço teórico e metodológico do pesquisador.

Uma expressão de que as categorias se construíram conforme visões particulares da sociedade e, particularmente ao se referir a ciência a cada pesquisador, embutida na singularidade de cada âmbito cultural 
a partir das relações de acordo com o espaço e tempo desiguais, tratamos brevemente da origem da categoria espaço, que mais tarde poderá ser relacionada a origem da própria categoria território.

Salientamos a pesquisa realizada por Saquet (2013), na qual é estudado várias obras centradas no conceito de território considerando diversos autores apontados como fundamentais na renovação da geografia e de outras ciências, com isso, ele coloca que:

\begin{abstract}
[...] todos trabalham, embora com concepções diferentes, com a ideia da construção social do território: Jean Gottmann, Giuseppe Dematteis, Francesco Indovina, Donatela Calabim Massimo Quaini, Alberto Magnaghi, Claude Raffestin, Robert Sack, Edward Soja, Milton Santos, Bertha Becker, Manuel Correia de Andrade, Arnaldo Bagnasco, Gilles Deleuze, Félix Guattari, entre outros e outras. Para nós, a centralidade do homem está muito clara e bem trabalhada por vários autores que nos antecederam, substantivando histórica e socialmente, na relação sociedade-natureza, a formação dos territórios, das paisagens, das regiões, dos lugares e dos espaços geográficos. (2013, p.49)
\end{abstract}

Desse modo, é relevante considerarmos dentro da discussão o conceito de espaço e a importância que ele carrega quando analisado juntamente ao território. Raffestin (1993) já enfatizava que o espaço e o território não são termos equivalentes:

\footnotetext{
É essencial compreender bem que o espaço é anterior ao território. O território se forma a partir do espaço, é o resultado de uma ação conduzida por um ator sintagmático (ator que realiza um programa) em qualquer nível. Ao se apropriar de um espaço, concreta ou abstratamente (por exemplo, pela representação), o ator "territorializa" o espaço. [...] O território nessa perspectiva é um espaço onde se projetou um trabalho, seja energia e informação, e que, por conseqüência, revela relações marcadas pelo poder. O espaço é a "prisão original", o território é a prisão que os homens constroem para si. $(1993$, p. 73, 74)
}

Nota-se que o autor vai além, a visão de que: "ao se apropriar do espaço concreta ou abstratamente o mesmo se torna territorializado", Raffestin deixa claro ao ressaltar a presença do território com o "poder". A criação do homem em cima da "prisão original" ou até mesmo "espaço natural" já pré-existente a ação humana, o espaço se transforma em território, e se torna a prisão do homem a partir das manifestações de todas as relações que nele são embutidas.

Observamos que a partir da década de 1970 o conceito de espaço começou a constituir-se como um tema central para os geógrafos, passando a ser perspectiva transformadora que contrapõem a ordem estabelecida e, contudo, sugere a construção de uma visão integradora do espaço. Nesse contexto, a preocupação dos geógrafos foi elaborar e pensar a construção de uma visão integradora para análise do espaço pautada nas relações sociais de produção. No caso de Raffestin (1993) o autor se apoiou no conceito de espaço, e entendia que o espaço é anterior a qualquer ação, o espaço é, de certa forma, "dado" como se fosse uma matéria-prima. O espaço é tido como um local de possibilidades é a realidade material que antecede qualquer prática ou ação. Segundo Raffestin (1993), o território se apoia no espaço, mas não é o espaço. É uma produção, a partir do espaço. Ora, a produção, por causa de todas as relações que envolve, se inscreve num campo de poder. 
A partir do momento que um ator (do Estado ao indivíduo) intervém e manifesta qualquer projeto no espaço, é revelada a imagem desejada de um território, ou seja, cria-se um local de relações, essas relações são mediadas por diversos meios, a língua é um deles. A língua, como uma forma de poder da identidade cultural de um povo, pode ser caracterizada segundo o autor, como um sistema sêmico. Raffestin afima que:

[...] todo projeto é sustentado por um conhecimento e uma prática, isto é, por ações e/ou comportamentos que, é claro, supõem a posse de códigos, de sistemas sêmicos. É por esses sistemas sêmicos que se realizam as objetivações do espaço, que são processos sociais. (1993, p. 145)

Toda prática espacial, induzida por um sistema de ações se traduz por uma "produção territorial". Todo processo de construção do território em sua materialidade se transforma em um instrumento de poder. A concepção de Raffestin (1993) de território pauta-se no pressuposto: possuidor de superfícies (tessituras), pontos (nós) e redes, esses sistemas possibilitam a integração e a coesão dos territórios os quais, como já visto, são produzidos por diversos atores, e também em quaisquer escalas. O território é um espaço trabalhado, formado pelos pontos, linhas e superfícies. Detém identidade, independente de tantas representações e quantos forem os autores que as planejem.

A representação exposta, é um conjunto definido em relação aos objetivos de um ou mais atores, pois com a construção desta ideia, o "espaço" não se encontra mais unicamente isolado. É tratado como "espaço construído pelo ator" que executa suas relações na realidade material por meio de um sistema sêmico. Dessa forma, Raffestin (1993) afirma que o espaço representado não é mais o espaço, mas a imagem do espaço, ou melhor, do território visto e/ou vivido. É, em suma, as territorialidades, o espaço que se tornou o território de um ator, desde que tomado numa relação social de comunicação.

No mesmo viés, Saquet (2009) ao discutir as obras de Raffestin (1976 e 1978) discorre que o autor faz um esforço metodológico para articular territorialidades materiais e ideológicas. A territorialidade é compreendida como relacional e dinâmica, mudando no tempo e no espaço, conforme as características de cada sociedade.

Como já visto, Raffestin (1993) coloca que o espaço, as redes de circulação-comunicação, as relações de poder, atividades produtivas das representações simbólicas e as malhas, são fatores que efetivam a produção do território, ou seja, o território é resultado das territorialidades efetivadas pelo homem. Desse modo, a territorialidade carrega significado das relações sociais (sejam elas equilibradas ou não) que, historicamente, resultam na produção de cada território. Com isso, Saquet (2008) coloca que numa concepção distinta, no que se refere à relação espaço-território, Raffestin dicotomiza estas duas dimensões ontológicas da dinâmica social e suas objetivações e subjetivações. 
Diferentemente de Raffestin, em 1988, Santos recorta o espaço, ao pontuar o território e o espaço como dois níveis diferentes da organização socioespacial. O espaço é uma realidade relacional que envolve, mediante o trabalho, a natureza e a sociedade. Já o território, surge como um conceito subjacente composto por variáveis que se constituem na configuração territorial:

Formada pela constelação de recursos naturais, lagos, rios, planícies, montanhas, florestas e também de recursos criados: estradas de ferro e de rodagem, condutos de toda ordem, barragens, açudes, cidades, o que for. É esse conjunto de todas as coisas arranjadas em sistema que forma a configuração territorial cuja realidade e extensão se confundem com o próprio território de um país. (SANTOS, 1988, p.75-76)

Na mesma obra, o autor faz um destaque ao tempo histórico, reafirmando a diferenciação existente na produção de territórios quando incluídos os contextos subjetivos e históricos. Cria-se periodizações do espaço dando significado ao território de formas (naturais e artificiais), relações sociais, fluxos e fixos; produto histórico modelado por cada sociedade, com certa configuração e delimitação. Cabe ressaltar que Santos recorta o espaço em territórios sem separá-los, os territórios estão no espaço geográfico (Saquet, 2008).

Após esse período, em 1994, Santos retoma o conceito de território a partir de novos significados. Em sua obra intitulada 0 retorno do território de 1994, o autor evidencia o conceito de território usado, o que acaba trazendo maior abrangência a visão por considerar dentro da discussão uma perspectiva além da restrita Estado-Nação, elevando sua análise ao uso e ao controle social no território podendo ser compreendido, de acordo com Saquet (2008) como sinônimo de espaço geográfico socialmente organizado ou, ainda, como quadro de vida híbrido (onde vários elementos se entrecruzam).

Quando discorremos sobre as articulações entre um conceito e outro, visamos mostrar a relevância da importância do uso, assim como Saquet mencionara:

Tal diferenciação é necessária, porém é fundamental reconhecer que espaço e território não estão separados: um está no outro. O espaço é indispensável para a apropriação e produção do território, (...) os conceitos não podem ser trabalhados separadamente e cada conjugação precisa ser definida por cada pesquisador ou grupo de estudos. Defini-los desta ou daquela maneira, portanto, é uma questão epistemológica, ontológica e política. Há diferentes abordagens e concepções de poder, de território e de territorialidade. (SAQUET, 2008, p. 83)

É evidente que há diversos entendimentos e interpretações sobre o conceito território. Fato que comprova tal afirmação são autores que produzem textos para procurar cada vez esclarecer o conceito e a temática da melhor maneira. Nesse caso, um grande exemplo é analise realizada por Souza (2009), intitulado: "Território" da divergência (e da confusão): em torno das imprecisas fronteiras de um conceito fundamental, no qual é discorrido as várias formas que o conceito território é abordado, tal como o tempo (contexto histórico) e particularidade que cada autor utiliza. 
Entendemos que a busca por identificar um único significado para o conceito será longa, já que identificamos no começo deste trabalho, que essa categoria de análise geográfica - o território é passível de diversas interpretações, pois, são embutidas na singularidade de cada âmbito cultural, a partir de espaço e tempo desiguais dos autores que dele se apropriam, que subentende a base teórica e metodológica dos pesquisadores. Mas não é por essa razão que deixamos de percorrer o caminho do qual esclarece e ampara a presente discussão.

Todas as discussões colocam em pauta os diversos ângulos que o conceito pode assumir, mas não deixam de mencionar sobre dois objetos chave na presente discussão: o território objetivo (material) e o subjetivo (imaterial).

Tendo em conta que autores importantes na construção do conhecimento geográfico como Haesbaert, Saquet e Milton Santos, entre outros, discutem este ponto de vista, é a partir desta concepção que o território está fundamentado neste artigo.

Nesse sentido, realiza-se discussões em torno do conceito dentro de uma visão imaterial. Visão esta, que é abordada a partir do olhar da Geografia Política, para não ocorrer enganos advindos de interpretações na Geografia Cultural. Assim como pontua Haesbaert:

\footnotetext{
A Geografia Cultural ao privilegiar a dimensão simbólica ou o campo das representações, utiliza muito mais outros conceitos, como paisagem ou lugar, do que território. Já na Geografia Política, território e mesmo territorialidade são tidos como conceitos fundamentais ( 2004, p.62)
}

Percebemos que a partir da visão objetiva, é colocado a importância do território no que se refere a delimitações político administrativa - que não deixa de ser importante, no que se trata sobre efetivação das ferramentas de planejamento e gestão. Afirma Freund (1977):

\begin{abstract}
A atividade política se define, em primeiro lugar, pelo fato de se desenrolar no interior de um território delimitado. [...] as fronteiras [...] podem ser variáveis; entretanto, sem a existência de um território que particularize o agrupamento, não se poderia falar de política. (...). Pode-se, pois, definir a política como atividade que reivindica para a autoridade instalada em um território o direito de domínio, que é a manifestação concreta e empírica do poderio. [...] Esse poderio e esse domínio segundo Max Weber, só se tornam políticos quando a vontade se orienta significantemente em função de um agrupamento territorial, com vistas a realizar um fim, que só tem sentido pela existência desse agrupamento (Apud HAESBAERT, 2016, p. 63)
\end{abstract}

Entendemos o território como objeto de análise e palco onde ocorrem todas as manifestações identitárias e apropriações deste espaço. Da mesma forma que o território é um espaço de identidade, é também um lugar de poder. Determinar seus limites, alterar sua fronteira pode ser considerado como sinônimo de dominação, de controle. Conforme coloca Andrade (2004), o território:

[...] está muito ligado a ideia de domínio ou de gestão de uma determinada área. Assim, deve-se ligar sempre a ideia de território à ideia de poder, quer se faça referência ao poder público, estatal, quer ao 
poder das grandes empresas que estendem os seus tentáculos por grandes áreas territoriais ignorando fronteiras políticas. (2004, p. 19)

Mais que isto, o território segundo Andrade (2004), da às pessoas que nele habitam a consciência de sua participação, provocando um sentimento de territorialidade que, de forma subjetiva, cria uma consciência de confraternização entre as mesmas.

Nessa compreensão, a territorialidade acaba assumindo um importante papel para o andamento da discussão, já que Raffestin (1993) coloca que os homens "vivem", ao mesmo tempo, o processo territorial e o produto territorial por intermédio de um sistema de relações existências e/ou produtivistas. À vista disso, sabemos que no território se convergem dimensões individuais e sociais, os indivíduos compartilham e constroem no espaço as ações e intervenções que torna possível e legítima a territorialidade. Soja (1971) (apud Raffestin,1993) define a territorialidade de maneira conclusiva como um fenômeno de comportamento associado à organização do espaço em esferas de influência ou em territórios nitidamente diferenciados, considerados distintos e exclusivos, ao menos parcialmente, por seus ocupantes ou pelos que os definem.

Essa distinção nos territórios, que os tornam exclusivos e heterogêneos, são resultados da ação do indivíduo, é a particularidade na ação de cada grupo ou indivíduo que dá a característica exclusiva para cada territorialidade.

Uma maneira e orientação que Raffestin (2003) encontra para identificar os territórios e as territorialidades destacando as heterogeneidades e os traços identitários dos grupos inseridos nestas áreas, é sistematizando o território em quatro níveis:

\begin{abstract}
a) O território do cotidiano: é o território atual, de todos os dias, no qual se garante a satisfação das necessidades. É caracterizado mais pelas descontinuidades e, por isso, pode ser considerado um arquipélago de lugares isolados uns dos outros.

b) $O$ território das trocas: há uma articulação entre o regional, nacional e internacional através da circulação de mercadorias. O território é aberto e fluído e está em constante movimento de mudanças. c) O território de referência: é material e imaterial; histórico e imaginário, subjetivo (memória individual e/ou coletiva). "O território de referência é justamente aquele dos antecedentes" (Idem, p.7). Não é o território que se habita, mas aquele que se habitou ou se conhece através de leituras e da memória. São imagens que nutrem a identidade atual.

d) O território sagrado: está ligado à religião e à política, como ocorre em Jerusalém e Roma. Nas festas e cerimônias também se efetivam sacralidades, territorialidades, rituais que caracterizam traços indenitários. (apud Saquet, 2008, p.84)
\end{abstract}

É possível notar que essas distinções objetivam a desagregação do conceito em vários significados. Esta é uma das maneiras que Raffestin (2003) encontra de explicar o território ressaltando suas particularidades. Nitidamente apresentam heterogeneidade e os traços específicos de cada grupo social. São territórios que se coincidem e que se sobrepõe. São caracterizados pelo controle e pelo domínio, pela apropriação e pela referência, pela circulação e pela comunicação, ou seja, por estratégias sociais que envolvem as relações de poder, materiais e imateriais, historicamente construídas (Saquet, 2008). 
No mesmo sentido que Raffestin (2003) procura explicar o território em níveis, Haesbaert (2016), expõe várias noções sobre o território. Se enquadrando na proposta desta discussão, o autor elucida e deixa palpável a noção do conceito. Dessa forma, ele busca dar subsídios para esclarecer o território agrupando as noções ante citadas em três vertentes básicas:

\begin{abstract}
- política (referida às relações espaço-poder em geral) ou jurídico-política (relativa também a todas as relações espaço-poder institucionalizadas): a mais difundida, onde o território é visto como um espaço delimitado e controlado através do qual se exerce um determinado poder, na maioria das vezes - mas não exclusivamente - relacionado ao poder político do Estado.

- cultural (muitas vezes culturalista) ou simbólico-cultural: prioriza a dimensão simbólica e mais subjetiva, em que o território é visto, sobretudo, como o produto da apropriação/valorização simbólica de um grupo em relação ao seu espaço vivido

- econômica (muitas vezes economicista): menos difundida, enfatiza a dimensão espacial das relações econômicas, o território como fonte de recursos e/ou incorporado no embate entre classes sociais e na relação capital-trabalho, como produto da divisão "territorial" do trabalho por exemplo. ( 2016, p. 40)
\end{abstract}

Nessa perspectiva, encontramos maior acessibilidade para discorrer a temática dentro do raciocínio territorial que está sendo pleiteado. Ao fazer relação entre as três dimensões, Haesbaert (2016) apresenta um modelo do qual podemos utilizar para chegarmos ao objetivo proposto de pensamos o território como pressuposto para a territorialização das políticas sociais. Embora reconhecemos a importância desta distinção entre as dimensões mais usuais sobre o território, é importante organizarmos o raciocínio a partir de outro patamar mais amplo, em que estas dimensões se inserem dentro da fundamentação filosófica de cada abordagem (Haesbaert, 2016).

Sendo assim, adotamos a perspectiva teórica de conceituação do território segundo:

a) O binômio materialismo-idealismo, desdobrado em função de duas outras perspectivas: i. a visão que denominamos "parcial" de território, ao enfatizar uma dimensão (seja a "natural", a econômica, a política ou a cultural); ii. A perspectiva "integradora" de território, na resposta a problemáticas que "condensadas" através do espaço, envolvem conjuntamente todas aquelas esferas. b) O binômio espaço-tempo, em dois sentidos: i. seu caráter mais absoluto ou relacional: seja no sentido de incorporar ou não a dinâmica temporal (relativizadora), seja na distinção entre entidade físico-material (como "coisa" ou objeto) e social-histórica (como relação); ii. Sua historicidade e geograficidade, isto é, se se trata de um componente ou condição geral de qualquer sociedade e espaço geográfico ou se está historicamente circunscrito a determinado(s) período(s) social(is) e/ou espaço(s) geográfico(s). (HAESBAERT, 2016, p.41)

O binômio materialismo-idealismo ao se desdobrar em duas visões (i e ii) simplifica e organiza a vertente da qual trabalhamos. A primeira ao tratar das três vertentes mencionadas anteriormente, incorpora, mesmo que de maneira parcial, as três direções para qual o território se destina. Enquanto a ' segunda trabalha com a visão "integradora" do território, ou seja, ela envolve todas as esferas.

Dentro desta lógica, na defesa de uma abordagem geográfica integradora e "totalizante" como já colocara Santos que utilizaremos o conceito de "território usado", este, como correlato direto de "espaço geográfico" (Santos, et al., 2000). 
Embora tenhamos visto o quão abrangente a conceituação possa ser, e quantos significados esta possa vir a trazer, o geógrafo Milton Santos ao colocar o papel da geografia e sua possibilidade de intervenção e transformação da sociedade, atenta para a abrangência dos conceitos, pois se a conceituação não é abrangente em todas as formas de relação da sociedade com seu meio, as intervenções serão apenas parciais ou funcionais, e sua eficácia será limitada no tempo (Santos, et al. 2000).

Podemos afirmar que geografia por certo tempo esteve limitada a ser interpretada como a ciência exata e das localizações, dessa forma, de acordo com Santos, a disciplina acaba limitando-se no rol das relações que se dão entre o homem e o meio.

Foi por isso, que propusemos considerar o espaço geográfico não como sinônimo de território, mas como território usado; este é tanto o resultado do processo histórico quanto a base material e social das novas ações humanas. Tal ponto de vista permite uma consideração abrangente da totalidade das causas e dos efeitos do processo socioterritorial. (SANTOS et al., 2000, p.104)

Santos ainda completa:

O território usado constitui-se como um todo complexo onde se tece uma trama de relações complementares e conflitantes. Daí o vigor do conceito, convidando a pensar processualmente as relações estabelecidas entre o lugar, a formação socioespacial e o mundo. (SANTOS et al. 2000, p.105)

É nesta perspectiva que propomos a seguinte discussão, a ideia de "território usado" que Milton Santos coloca e que Maria Adélia A. de Souza posteriormente apresenta. É a relação mais singular que a Geografia faz ao se aproximar e prover instrumentos de análise espacial para as políticas sociais, quebrando, inclusive, a ideia de que a ciência geográfica é somente uma ciência exata e que sua função se limitaria apenas às localizações.

As categorias de análise ajudam a Geografia a transcender seu diálogo com outras ciências, essa transdisciplinaridade pode ser notada quando usamos seus próprios conceitos para esclarecer ações de outras áreas do conhecimento. É inegável que o conceito tem retornado às ciências sociais de forma a tornar-se presente em importantes políticas públicas nas diferentes escalas de poder (Ruckert, 2010, p. 21). Nessa perspectiva, Koga e Nakano complementam:

Incorporar a perspectiva territorial na formulação, na implementação, no monitoramento, na avaliação e na revisão de políticas públicas implica necessariamente manejar as potencialidades ativas dos territórios na constituição de processos e relações sociais e de poder. ( 2005, p.68)

Entende-se manejar as potencialidades ativas dos territórios como meios de elaborar estratégias para alavancar o território a partir das suas particularidades conhecendo sua realidade e tornando-o funcional ao compreender suas relações internas existentes. 
Com isso, podemos afirmar que o espaço geográfico, o território e agora o território usado que Milton Santos traz, nos auxilia a compreender situações que facilitam a leitura territorial e o mais importante, promove o aprimoramento e o desenvolvimento de ferramentas de gestão. E é a partir do olhar da gestão que notamos a necessidade de estabelecer relações com o território - tendo em conta que poder, gestão e controle, acabam fazendo parte de um mesmo objeto.

\title{
Território como sustentáculo na elaboração e aplicabilidade das políticas sociais
}

Como já exposto, apreendemos que o conceito território extrapola suas fronteiras tanto conceituais como suas fronteiras geográficas, ele permite a noção da totalidade, bem como das especificidades presentes em cada porção em que se distribui. Santos alude que o território é o lugar em que desembocam todas as ações, todas as paixões, todos os poderes, todas as forças, todas as fraquezas, isto é, onde a história do homem plenamente se realiza a partir das manifestações da sua existência (Santos, 1999).

O Na premissa de Santos o território constitui-se em um conceito híbrido, ele é determinado pela noção material (física) e pela relação que os homens estabelecem realizando a constante (re)construção do local, ou seja, passa a adotar uma concepção imaterial, assim:

\footnotetext{
O território não é apenas o conjunto de sistemas naturais e de sistemas de coisas superpostas. O território tem que ser entendido como o território usado, não o território em si. O território usado é o chão mais a identidade. A identidade é o sentimento de pertencer aquilo que nos pertence. $O$ território é o fundamento do trabalho, o lugar da residência, das trocas materiais e espirituais e do exercício da vida (SANTOS, 1999, p.8)
}

E é nessa perspectiva que o território passa a ser apropriado pelas políticas sociais como um conceito estratégico para gestão, visto que a maior necessidade destas políticas é identificar todas as questões objetivas e subjetivas presentes em seu território, assim como detectar todas as ofertas e demandas que o mesmo dispõe. Ao tratar sobre apreender as reais necessidades intrínsecas no território, Koga afirma:

\begin{abstract}
A dimensão territorial traz elementos que permitem uma perspectiva de totalidade da questão social: já que trabalha não somente com os aspectos das necessidades, como se refere às próprias relações estabelecidas entre os sujeitos e seu cotidiano de vivência, esta relação dinâmica se contrapõe à corriqueira e simplista noção de necessitados ou carentes como comumente se referem as políticas direcionadas aos pobres, que os destitui da condição de sujeito. (2003, p. 39)
\end{abstract}

Com a contribuição geográfica, o território para as políticas sociais, mais objetivamente para de Assistência Social, passa a esclarecer que seu espaço é um conjunto de possibilidades, as quais auxiliam ao desenvolvimento do homem, de suas ações e produções. Contudo, essa potencialidade que o espaço ao ser analisado dispõe, só passa a adquirir forma a partir do uso que o homem faz dele - e o território passa a se tornar usado quando identificada as relações sociais que o justificaram. Com isso, notamos que ao pensar as 
políticas de âmbito da Assistência Social que levem em consideração o território usado, "indica-se um mecanismo de intervenção social a necessidade de conhecer e reconhecer as demandas dos indivíduos, suas estratégias de sobrevivência, suas barreiras de convívio e relação " (Santos \& Pastor, 2016, p.138).

Por fim, fica claro a importância do território no uso das políticas públicas/sociais no que passa a ser uma ferramenta estratégica que define com detalhamento as lógicas da organização social. Dentro dessas novas lógicas de organização, tal como gestão e provisão no campo das ações de assistência social. Nascimento e Melazzo (2013) fazem a interpretação da NOB-SUAS/2005 ${ }^{1}$ deixando claro a proposta que define com detalhamento os elementos relevantes da organização destacando o território como base de organização do sistema, cujos serviços devem obedecer à lógica de proximidade do cidadão e localizar-se em territórios de incidência de vulnerabilidade e riscos para a população. Com isso, o território passa, assim, a ser considerado como base de organização do SUAS e suporte paras as tomadas de decisão obedecendo a lógica do planejamento estratégico.

No contexto de pensar a territorialização das políticas públicas cabe sublinhar o papel que direciona a descentralização para a efetividade territorial da política social, pois se considera a política de assistência social para conquistar categorias mínimas de efetividade em suas urgências, precisa ser descentralizada, com a descentralização do poder entre as esferas governamentais e locais há ganho na gestão e aumento das relações entre sociedade-estado, o que promove diversos desdobramentos que tangem uma reforma mais efetiva em que há participação da população, tal como, reformulações das políticas de proximidade proporcionando maior contato com a realidade presente em cada território. Antonello conclui que:

A contraposição à centralização do poder assenta-se na concepção moderna do federalismo que defende a potencialidade de intervenção dos governos locais em prol do atendimento direto à população, pautado na premissa que a proximidade da população promoveria um controle social das políticas públicas. (2012, p. 834)

No âmbito do SUAS e da política descentralizada no território, para a Assistência Social garantir-se como uma política pública afiançadora de direitos, o foco tem de ser transferido para a menor escala de análise disponível, identificando as famílias e seus membros a partir de seus territórios de vivência, pois, como visto, esse é o modo mais eficiente de interpretar a realidade da localidade em questão e identificar as demandas, sempre dando prioridade àquelas situações com os maiores registros de fragilidades e vulnerabilidades.

É dentro dessa perspectiva que surge a necessidade de relacionar as pessoas aos seus respectivos territórios, bem como aplicar metodologias que encontrem as demandas sociais que estão ocultadas e que ainda não foram identificadas. Por mais que os serviços da Assistência Social estejam presentes nos territórios

\footnotetext{
1 Norma Operacional Básica - Sistema Único de Assistência Social, aprovada em 2005, é um sistema descentralizado, participativo e não contributivo, que organiza e regula as responsabilidades de cada esfera do governo e da sociedade civil vinculados à Secretaria de Assistência Social.
} 
existem situações em que as instituições com suas ferramentas legais não podem amparar por não conseguir reconhecer os agravamentos que fogem dos mecanismos presentes nas ofertas dos serviços. As demandas estão em constante mudança e muitas vezes a oferta disponível por meios oficiais não identifica e acaba não contemplando as ocorrências mais subjetivas que se apresentam no território.

\section{CONSIDERAÇÕES FINAIS}

Pensar sobre o território e os conceitos norteadores para compreensão da aplicabilidade e efetividade das políticas sociais é fundamental para entender que informações quantitativas do território dito material são importantes para guiar a gestão dos órgãos públicos. Mas todo esse levantamento é apenas o ponto de partida, para conhecer o território, essa compreensão territorial só vai realmente ser efetiva quando a gestão colocar os pés no chão, caminhar pelo "território usado" de Milton Santos, vivenciar e compreender a realidade das pessoas que necessitam dos serviços socioassistenciais, pois como afirma Dirce Koga (2003, p. 258) - ao se referir às representações de médias e generalidades de informações - "[...] é preciso enxergar mais profundamente o que se passa no chão das desigualdades, onde figuram situações concretas de vida recheadas de enclaves mas também de potências". As potências necessitam ser levantadas, elas ressuscitam a potência local e dão subsídios para o aperfeiçoamento do local baseado no real. Evidentemente é uma tarefa difícil, mas não impossível, Santos (1999, p.11) já afirmava: “Não podemos realmente oferecer as fórmulas de entendimento do local. Oferecemos um quadro geral de reflexão a ser refeito localmente [...] as combinações locais são múltiplas."

A esperança da reconstrução de um espaço urbano mais integrador e solidário é necessário, a reelaboração da gestão de políticas sociais é uma meta que precisamos conquistar em nosso país, essa ação depende da sociedade civil aos governantes, dos gestores ao desenvolvimento de instrumentos facilitadores, para então fazermos o caminho inverso, e assim podermos compreender o global partindo do local.

\section{REFERÊNCIAS}

ANTONELLO, I. T. O entrelaçamento entre a descentralização das políticas públicas e as desigualdades territoriais no Paraná. In: VI SIMPGEO - Simpósio Paranaense de Pós-graduação e Pesquisa em Geografia - Ciência, Sociedade e Tecnologia na Perspectiva da Análise Geográfica. Guarapuava, 2012, Anais... Guarapuava: Ed. Da UNICENTRO, 2012. v.I, p.831 - 846. CD ROM.

ANDRADE, Manuel Correia de. A questão do território no Brasil. 3. São Paulo: Hucitec, 2004.

CORREA, R. L. Geografia: conceitos e temas. 2o ed. - Rio de Janeiro: Bertrand Brasil, 2000

HAESBAERT, Rogério. O mito da desterritorialização: do "fim dos territórios" à multiterritorialidade/ Rogério Haesbaert. - 10ā ed. Rio de Janeiro: Bertrand Brasil, 2016. 396p

HAESBAERT, R. e LIMONAD, E. O território em tempos de globalização. GeoUERJ, no 7, Vol. 3 (5), Rio de Janeiro: UERJ, 1o semestre de 1999, p. 7- 20. 
KOGA, Dirce. Medidas das Cidades - entre territórios de vida e territórios vividos. São Paulo: CORTEZ, 2003.

KOGA, Dirce e NAKANO Kazuo. Perspectivas Territoriais e Regionais para políticas públicas brasileiras. In A Abong nas Conferências 2005 - Criança e Adolescente - Assistência Social. Cadernos Abong, 2005.

LEFEBVRE, Henri. Espaço e política. Belo Horizonte: Editora UFMG, 2008.

NASCIMENTO, P. F. \& MELAZZO, E. S. Território: conceito estratégico na assistência social. Revista Serviço Social, Londrina, v. 16, n.1, P. 66-88, Jul/dez. 2013.

Raffestin, Claude. Por uma geografia do poder. Saõ Paulo: Ática, 1993.

ROCHA, J. C Diálogo entre as categorias da Geografia: espaço, território e paisagem. Caminhos da Geografia, Uberlândia; v.9 n. 27 sets/2008. p.128-142. Disponível em: http://www.seer.ufu.br/index.php/caminhosdegeografia/article/viewFile/15724/8897 . Acesso em: agosto de 2017

RUCKERT, A. A. Usos do território e políticas territoriais contemporâneas: alguns cenários no Brasil, União Europeia e MERCOSUL. In: Firkowski,Olga Lucia C. de Freitas (org). Transformações territoriais: experiências e desafios. Rio de Janeiro: Letra Capital, 2010, p. $17-32$.

SANTOS, Milton. Metamorfoses do espaço habitado. São Paulo: Hucitec, 1988.

SANTOS, M. O dinheiro e o território. GEOgraphia, Rio de Janeiro, v. 1, n. 1, p. 7-13, 1999. Disponível em: <http://www.geographia.uff.br/index.php/geographia/article/view/2>. Acesso em: 25 jul. 2017.

SANTOS, M. et al. O Papel Ativo da Geografia: um manifesto. Florianópolis: XII Encontro Nacional de Geógrafos, Revista Território, Rio de Janeiro, ano V, n 9, Julho, 2000, p.103-109.

SANTOS, M. O retorno do territorio. En: OSAL : Observatorio Social de América Latina. Año 6 no. 16 (jun.2005- ). Buenos Aires : CLACSO, 2005

SANTOS \& PASTOR O. território como estratégia de gestão democrática na política de assistência social em Londrina-PR. In: Conserva, Marinalva de Sousa; Alves, Jolinda de Moraes; Silva, Emanuel Luiz Pereira da (Org.). Territórios em diálogo: os chãos como ponto de partida para as políticas sociais brasileiras [livro eletrônico]/- João Pessoa: Editora CCTA, 2016, p. 134-148.

SAQUET, M. A. \& SPOSITO, E. S. Por uma abordagem territorial. In: Territórios e territorialidades: teorias, processos e conflitos. Marcos Aurelio Saquet, Eliseu Savério Sposito (organizadores) --1.ed.-- São Paulo: Expressão Popular : UNESP. Programa de PósGraduação em Geografia, 2008. p. 73 - 94

SAQUET, M. A. Por uma abordagem territorial: continuando a reflexão in: SAQUET, M.A. (organizador). Estudos territoriais na ciência geográfica. 1ed. São Paulo: Outras Expressões, 2013, p. 47-74 